\title{
Frontiers
}

\section{in the Psychotherapy} of Trauma \& Dissociation

How Are Memories of Entrapment in Abuse Born? Andreas Laddis, MD

The Official Clinical Journal of the International Society for the Study of Trauma and Dissociation 


\section{Frontiers in the Psychotherapy of Trauma \& Dissociation}

The Official Clinical Journal of the ISSTD

\section{EDITOR}

ANDREAS LADDIS, MD, Private Practice and Faculty, Boston University, School of Public Health, Boston, Massachusetts, USA

\section{ASSOCIATE EDITOR}

MARTIN J DORAHY, PhD, Professor, Department of Psychology, University of Canterbury, Christchurch, New Zealand and The Cannan Institute, Brisbane, Australia

Frontiers in the Psychotherapy of Trauma \& Dissociation is published by the International Society for the Study of Trauma and Dissociation, Inc., 1420 New York Ave NW, Fifth Floor, Washington, DC 20005.

\section{Annual Subscription, Volume 3, 2019}

Online subscription is part of the membership dues of the International Society for the Study of Trauma and Dissociation. Visit http://www.isst-d.org/default.asp?contentID=44.

Production and Advertising Office: ISSTD Headquarters, 1420 New York Ave NW, Fifth Floor, Washington, DC 20005.

Copyright @2019 International Society for the Study of Trauma and Dissociation. All rights reserved. No part of this publication may be reproduced, stored, transmitted, or disseminated in any for or by any means without prior written permission from the International Society for the Study of Trauma and Dissociation. The publisher assumes no responsibility for any statements of fact or opinion expressed in the published papers. The appearance of advertising in this journal does not constitute an endorsement or approval by the publisher, the editor, the editorial board, or the board of directors of the International Society for the Study of Trauma and Dissociation of the quality or value of the product advertised or of the claims made of it by its manufacturer.

Subscriptions to this journal are acquired through membership in the International Society for the Study of Trauma and Dissociation only.

Visit http:/ / www.isst-d.org/default.asp?contentID=45.

Permissions. For further information, please write to info@isst-d.org.

\section{EDITORIAL BOARD}

ELIZABETH S BOWMAN, MD, Editor Emerita, Journal of Trauma \& Dissociation, Adjunct Professor of Neurology, Indiana University School of Medicine, Indianapolis, Indiana, USA

LAURA S. BROWN, PhD, Private Practice, Seattle, Washington, USA

RICHARD A CHEFETZ, MD, Private Practice, Faculty and Founding Member Institute of Contemporary Psychotherapy \& Psychoanalysis, Distinguished Visiting Lecturer: William Alanson White Institute of Psychiatry, Psychoanalysis \& Psychology, New York City, USA

CONSTANCE J DALENBERG, PhD, Trauma Research Institute, California School of Professional Psychology, San Diego, California, USA

J.K. JUDITH DANIELS, PhD, Faculty of Behavioural and Social Sciences, University of Groningen, The Netherlands

STEVEN N GOLD, PhD, Professor, Center for Psychological Studies, and Founding Director, Trauma Resolution \& Integration Program, Nova Southeastern University, Fort Lauderdale, Florida, USA ELIZABETH B HEGEMAN, PhD, Professor, Department of Anthropology, John Jay College of Criminal Justice, New York, New York, USA 
RICHARD P. KLUFT, MD, PhD Private Practice and Clinical Professor of Psychiatry, Temple University School of Medicine; Faculty Member, Philadelphia Center for Psychoanalysis,

Philadelphia, Pennsylvania, USA

CHRISTA KRÜGER, MD, Professor of Psychiatry, University of Pretoria, Pretoria, Gauteng, South Africa

KARLEN LYONS-RUTH, PhD, Professor of Psychology, Harvard Medical School, Cambridge, Massachusetts, USA

ALFONSO MARTÍNEZ-TABOAS, PhD, Professor, Albizu University, San Juan, Puerto Rico

WARWICK MIDDLETON, MD, Adjunct Professor, Cannan Institute, Brisbane, Australia ELLERT

R. S. NœENHUIS, PhD, Department of Psychiatry and Outpatient Department Mental Health Care Drenthe, Assen, The Netherlands

SANDRA PAULSEN, PhD, Bainbridge Institute for Integrative Psychology, Bainbridge Island, Washington, USA

VEDAT SAR, MD, Professor of Psychiatry, Koç University School of Medicine (KUSOM), Istanbul, Turkey

JOYANNA SILBERG, PhD, Trauma Disorders Program, Sheppard Pratt Health Systems, Baltimore, Maryland, USA

ELI SOMER, PhD, Professor, School of Social Work, University of Haifa, Israel

KATHY STEELE, MN, CS, Private Practice, Atlanta, Georgia, USA

ONNO VAN DER HART, PhD Emeritus Professor of Psychopathology of Chronic Traumatization, Department of Clinical and Health Psychology, Utrecht University, Utrecht, The Netherlands VICTOR WELZANT, PsyD, Sheppard Pratt Health Systems, Trauma Disorders Program

\section{REVIEWERS}

JOHN BRIERE, PhD, Associate Professor of Psychiatry and Psychology, University of Southern California Keck School of Medicine, Los Angeles, California, USA

SHELDON IZKOWITZ, PhD, Clinical Associate Professor of Psychology and Clinical Consultant, Postdoctoral Program, New York University, New York City, USA and Teaching Faculty \& Supervisor of Psychotherapy and Psychoanalysis, National Institute for Psychotherapies, New York City, USA

MARY-ANNE KATE, PhD Researcher at University of New England, Australia; University of New England, New South Wales, Australia

ULRICH F. LANIUS, PhD, Private Practice, West Vancouver, British Columbia, Canada

\section{SUPPORTERS}

ISSTD thanks its generous supporters whose contributions have made this publication possible:

Andreas Laddis, MD, USA

\section{The \\ Cannan \\ Institute}

Cannan Institute, Australia Warwick

Middleton, MD, Australia

Dana Ross, MD, Canada

Martin J. Dorahy, PhD, New Zealand

Kate McMaugh, Australia

Sara Y. Krakauer, USA 


\title{
EDITORIAL
}

\section{How Are Memories of Entrapment in Abuse Born?}

\author{
ANDREAS LADDIS, MD \\ Editor for Frontiers in the Psychotherapy of Trauma and Dissociation
}

KEYWORDS entrapment in abuse, recovered memories, veracity

This month, Frontiers presents a collection of articles related to the paper Colin Ross published in our journal last year (Ross, 2018). That article's purpose was "to discuss the similarities and differences between maladaptive daydreaming and dissociative identity disorder (DID), and then to discuss possible implications ... in the treatment of complex cases of DID, particularly those with ... reported histories of satanic ritual abuse....[to consider that] maladaptive daydreaming, combined with the principle of therapeutic neutrality ... can help in the management of counter-transference..." (p. 161). The term "therapeutic neutrality" refers to the therapist's judgment about the veracity of memories of satanic ritual abuse (SRA).

Ross's article moved Alison Miller to write a commentary, which critiques his understanding of therapeutic neutrality as insufficiently neutral. She argues that Ross's illustration of his response to hearing memories of satanic ritual abuse shows implicit bias; it "sets up a dynamic that a therapist will believe and affirm some aspects of a client's story, but not others, which may put pressure on the [suggestible] client regarding what to believe." With her own brief illustration, Miller continues the 30-year old debate about our role as therapists in discerning which components of

Author Contact Information: Andreas Laddis, MD; Private Practice, Framingham, MA, USA; Boston University, School of Public Health, Boston, MA, USA; email: aladdis@ gmail.com. 
clients' memories were born of having experienced events that really constituted the practice of satanic ritual abuse. She reminds us that the debate was about balancing (a) the purpose of empowering clients to make sense of that themselves, with (b) protecting ourselves from the danger of speaking outside the office about believing clients' particular allegations, with implications for criminal justice and making social policy.

Seeking such a balance created much tension in the International Society for the Study of Trauma and Dissociation (ISSTD) over many years. It often led members to simplistically and pejoratively labeling one another as "believers" and "non-believers." That polarization found a formal expression when Special Interest Groups (SIGs) were created in ISSTD about eight years ago, one of them addressing the understanding and treatment of victims reporting ritual abuse and mind control (RAMC). In the past two years, ISSTD took effective measures to mitigate that polarization. It created opportunities for new debate, which are now grounded on recent progress made in (a) investigative and judicial findings about the reality of pervasive and clandestine organized abuse, sometimes in mystical settings; and (b) findings about the psychological laws of reconstructing memory of events over time. Reconstruction includes composing event-like memories from developments in various events, whether experienced in reality or in imagination (e.g., from suggestion or during maladaptive daydreaming).

In the same spirit of promoting reasonable and scholarly debate, I welcomed Miller's commentary and Ross's response that followed. In that response, Ross summarizes his concepts and technique of therapeutic neutrality from his original article to address Miller's concerns. He points out that the section about therapeutic neutrality was necessarily succinct because his article's primary object was how memories of satanic ritual abuse in persons with DID might reflect co-occurrence with maladaptive daydreaming.

I invited Eli Somer, who has pioneered the study of maladaptive daydreaming, to contribute a second commentary, in regard to Ross's treatment of the topic in the context of understanding memories of persons with DID. Both Somer's commentary and Ross's response expand from the co-occurrence of maladaptive daydreaming with DID to the co-occurrence with various kinds of dissociative experiences, for example, children's experience of seeing and touching an imaginary companion. Somer and Ross carry on an informative discussion about typologies of "dissociation" and what constitutes the passage from useful dissociation to disorder.

On the occasion of hosting Miller's commentary and Ross's response to her, I invited commentaries from two colleagues, Warwick Middleton and Michael Salter, who had played leading roles in the recent initiatives to mitigate the polarization in ISSTD. I asked them to write an account of their own personal experiences in the controversy and how they envision 
progress. Their commentaries are eloquent and exemplary for thoughtfulness and collegiality.

I see this collection of articles as a measure of maturity for Frontiers, for two reasons. The first is that commentaries, along with the authors' responses, greatly amplify and clarify the original article's purpose. Miller's and Somer's commentaries are the first since Frontiers' birth in the fall of 2017. A second reason is the opportunity to showcase the quality of debate in ISSTD on this very polarizing issue. We all understand that memories of organized abuse may be mostly inexact, inconsistent, even surrealistic, however, still indicative of having really suffered abuse by particular perpetrators and accomplices, who intended to terrify and harm the child. We all strive to understand what in the nature of entrapment in abuse and exploitation makes victims have inexact and inconsistent memories of it. All therapists among us strive to help clients ascertain the veracity of those particulars, as it may matter for their current lives.

\section{REFERENCES}

Ross, C. A. (2018). The potential relevance of maladaptive daydreaming in treatment of dissociative identity disorder in persons with ritual abuse and complex inner worlds. Frontiers in the Psychotherapy of Trauma and Dissociation, 2(1), 160-173. 